\title{
Effect of Retort Processing on Low Sodium Instant Noodle Seasoning Based on Oil-in-Water Emulsions
}

\author{
Melanie Cornelia $^{\mathrm{a}^{*}}$, Angeline Aprilina $^{\mathrm{a}}$, And Irene Triyanti $^{\mathrm{b}}$ \\ ${ }^{a}$ Food Technology Department, Pelita Harapan University, Faculty of Science and Technology, Indonesia \\ e Research and Development Department, PT. Nutrifood Indonesia \\ ${ }^{*}$ Corresponding author \\ melanie.cornelia@uph.edu \\ TEL: +62215460901 \\ FAX: +62215460901
}

Received: 20 October 2018; Published online: 18 April 2021

\begin{abstract}
Increasing consumption of instant noodles with high sodium content could elevate the risk of cardiovascular disease. Making instant noodle seasoning in the form of an oil-in-water emulsion was expected to improve the perception of salty taste without increasing the use of salt. However, the oil concentration in the emulsion affects the perception. The addition of antioxidant and retort processing was needed to overcome the nature of the emulsion that was quite susceptible to oxidation and microbial contamination. Preliminary research determined the optimum concentration of oil and antioxidant based on physical characteristics, the perception/gustation of saltiness, and emulsion oxidative stability and the results were used for further research. The final part of the research determined the effects of retort processing on emulsion stability, the perception of saltiness, and the degree of microbial contamination. Three different oil concentrations $(26,27$, and 28\%) and three types of antioxidants (natural vitamin E, ascorbyl palmitate and mixed tocopherol) were applied to the instant noodle seasoning oil-in-water emulsions. The results showed that using $28 \%$ oil and mixed tocopherol had the most stability, was more viscous, and had optimum salty taste perception, which significantly extended the shelf-life of the emulsion compared with the others. Retort processing for 21.5 minutes in $123.5^{\circ} \mathrm{C}$ was applied to the seasoning emulsion with $28 \%$ oil content and mixed tocopherol. Although, the microbial contamination was significantly reduced, neither the stability of emulsion nor the perception of salty taste was significantly changed by the process.
\end{abstract}

Keywords: Instant noodle; O/W emulsion; Retort; Salt reduction; Seasoning

\section{Introduction}

The consumption rate of instant noodles is increasing globally, including in Indonesia. There is an estimated $1950 \mathrm{mg}$ of sodium in one serving size of $120 \mathrm{~g}$ instant noodle, which exceeds the Recommended Dietary Allowance for common sodium intake of $1500 \mathrm{mg}$ per day (BPOM, 2016; Daniel, Momoh, Friday, Okpachi, \& Ejembi, 2014). High consumption of instant noodles can raise cardiometabolic risk which may lead to cardiovascular disease (Shin et al., 2014). Thus, a reduction in sodium intake is recommended to reduce and control blood pressure to avoid the risk of cardiovascular disease, which is the leading cause of death. One of the ways to reduce these risks is to make low sodium instant noodle seasoning in the form of an oil-in-water emulsion. Using an oil-in-water emulsion can increase the perception of saltiness in foods without in- 
creasing the use of $\mathrm{NaCl}$ (Torrico \& Prinyawiwatkul, 2015). The presence of fat in the emulsion, which contributes to the mouthfeel, would tighten the binding of substrate $\left(\mathrm{Na}^{+}\right)$with receptors in taste buds and enhance neurotransmitter transport, resulting in the transfer of the neuron electric signal to brain as salty perception. However, instant noodle seasoning emulsion tends to have low stability and poor sensory characteristics. Hence, instant noodle seasoning in the form of an emulsion is rarely found in the market (Bakry et al., 2015). The oil used in the emulsion is susceptible to oxidation, which would decrease the quality of the product due to the rancidity that occurs (Wasowicz et al., 2004). Therefore, the addition of antioxidant would prevent the rancidity. Moreover, the highwater content in the emulsion also leads to the proliferation of microorganisms, such as bacteria, yeasts and molds, and can also trigger deterioration due to oxidation (Lund, Baird-Parker, Baird-Parker, Gould, \& Gould, 2000). Retort processing is applied to many food products to ensure their safety from microorganism contamination (Rahman, 2013) and instant noodle seasoning could be further improved using retort processing. The preliminary aim of this research was to obtain the optimum concentration of oil and antioxidant based on physical characteristic, the perception/gustation of saltiness, and emulsion oxidative stability and the results of which were used in the main research. The main aim was to determine the effects of retort processing on emulsion stability, the perception of saltiness, and the degree of microbial contamination in the emulsion.

\section{Materials and Methods}

Materials used were palm oil, instant noodle seasoning premix powder (reduced sodium 25\%), control instant noodle seasoning premix powder, instant noodle, sweet soy sauce, xanthan gum, soy protein isolate (SPI), natural vitamin E, ascorbyl palmitate, mixed tocopherol, water, standard plate count agar, yeast extract glucose chloramphenicol agar, tap water, standard potassium solution $1000 \mathrm{ppm}$, standard sodium solution 400 ppm, phosphate buffer, alcohol, re- tortable pouches, and filter paper. Emulsions were prepared using a Silverson L5T High Shear mixer (Silverson, USA). Viscosity was measured using a Brookfield DV-E viscometer.

\subsection{Preliminary Research}

\section{Emulsion Preparation and Emulsification Process}

First, the aqueous phase was prepared using a constant concentration of premix seasoning powder, sweet soy sauce, SPI, xanthan gum, and antioxidant. The oil phase was prepared by weighing palm oil to 26,27 , and $28 \%$ of the total weight of the emulsion; the water used was calculated based on the oil concentration. The process of making instant noodle seasoning emulsion was done according to the method described by Arnold, Teja, and Yudianto (2018) with modification. The premix (sweet soy sauce 16.67\% $(\mathrm{w} / \mathrm{w})$, premix seasoning powder $26.19 \%(\mathrm{w} / \mathrm{w})$, SPI $1 \%(\mathrm{w} / \mathrm{w})$, xanthan gum $0.1 \%(\mathrm{w} / \mathrm{w})$ from aqueous phase, oil $(26,27,28 \%)(\mathrm{w} / \mathrm{w})$, antioxidant (natural vitamin $\mathrm{E}$, ascorbyl palmitate, mixed tocopherol) $10 \mathrm{ppm}$ and water $(\mathrm{w} / \mathrm{w})$ ) were dry-mixed, while distilled water was heated to $70^{\circ} \mathrm{C}$. Then, soy sauce and the solid mixture were slowly poured into the water. The result of this mixing was referred to as liquid phase. Separately, the oil was mixed with the antioxidant to be used. Then the liquid and the oil mixture was homogenized using the high shear mixer for 10 minutes at $4000 \mathrm{rpm}$.

The emulsion produced was analyzed further for its sensory properties (saltiness evaluation). Sensory evaluation was carried out by thirty trained panellists on the same day as the emulsion sample production in the form of evaluating the saltiness perception of sample with scale test. The sample presented was in the form of a mixture of seasoned emulsion and instant noodles that had been boiled for the evaluation of saltiness. Panellists scores the perceived saltiness on a scale ranging from zero (very unsalty) to 15 (very salty). Viscosity was measured by Brookfield DV-E Viscometer, and emulsion stability was measured by creaming at $0,7,14,21$ and 28 days. Estimating shelf-life was determined by theAccelerated 
shelf-life Testing (ASLT) method with the Arrhenius equation. The stability of the product was observed based on its critical parameters in the form of rancidity intensity during storage which was affected by the increase in temperature (Kilcast \& Subramaniam, 2000).

The shelf-life of the sample was determined based on critical parameters in the form of sample oxidation level which is indicated by the rancidity value and expressed as separation fraction and for oxidation stability/shelf-life evaluation. Samples were stored at three different temperatures, namely $27^{\circ} \mathrm{C}, 37^{\circ} \mathrm{C}$ and $47^{\circ} \mathrm{C}$ for 28 days, and the value of rancidity was observed on days 0 , $7.14,21$, and 28 . The results plotted to determine shelf-life of the product at a certain temperature, using the following equation:

$$
K=K_{\infty} \cdot e^{\frac{-E a}{R T}}
$$

\subsection{Main Research}

\section{Retort Processing}

Retorting was carried out based on the method performed by Chung, Cha, Koo, Ahn, and Choi (1991) with modifications. Liquid phase and the oil mixture was homogenized using high shear mixer for 10 minutes at $4000 \mathrm{rpm}$. A total of 20 grams of seasoning emulsion (sweet soy sauce $16.67 \%$ (w/w); premix seasoning powder $26.19 \%$ $(\mathrm{w} / \mathrm{w})$; SPI $1 \%(\mathrm{w} / \mathrm{w})$; xanthan gum $0.1 \%(\mathrm{w} / \mathrm{w})$ from aqueous phase; oil $(\mathrm{w} / \mathrm{w})$, antioxidant 10 $\mathrm{ppm}$ and water $(\mathrm{w} / \mathrm{w}))$ were put into retortable pouches with dimensions of $9 \times 15 \mathrm{~cm}$. Retorting was carried out by autoclaving at $123.5^{\circ} \mathrm{C}$ for 21.5 minutes. Each retort process was carried out on 32 retortable pouches simultaneously. After the retort process was complete, the effects of the processing on the instant noodle seasoning emulsion were measured by saltiness evaluation, emulsion stability, the degree of microbial contamination by total plate count (TPC)and yeast and mold count (YMC), moisture and sodium content. The analysis was also carried out on the non-retorted seasoning emulsion as a comparative treatment.

\subsection{Replicates and statistical analysis}

The data were analyzed using software IBM SPSS Statistics 22, with replication of three times per treatment with pairing for the preliminary research (ANOVA), and using the independent samples T-test of two treatments with four replications with each pairing for the main research.

Statistical analysis of the sensory properties and the effect of retort process carried out by Analysis of Variance (one-way ANOVA). All values were stated as the mean $\pm \mathrm{SD}$ and statistical significance at $\alpha=0.05$

\section{Results and discussion}

\subsection{Preliminary Research}

In the preliminary research, there were nine formulations which consisted of a combination of three types of antioxidant and three oil concentrations. Nine formulations of seasoning emulsion were a combination of $26 \%$ to $27 \%$ and $28 \%$ oil (designated A, B, and $\mathrm{C}$ respectively), and the natural antioxidants vitamin E, ascorbyl palmitate and mixed tocopherols indicated by 1, 2, and 3 . Thus the experimental treatments were designated A-1, A-2, A-3, B-1, B-2, B-3, C-1, C-2 and $\mathrm{C}-3$ respectively. Analysis of the physical characteristics of the emulsion in the form of stability and viscosity, sensory saltiness and shelf-life of the emulsion based on the stability of oxidation was done to determine the best formulation to be used in the main study stage.

\section{Viscosity}

Based on the statistical analysis, the viscosity of emulsions was significantly affected by oil concentration, whereas type of antioxidant and the interaction between oil concentration and type of antioxidant were not significantly affected the viscosity of emulsions $(\alpha=0.05)$. Viscosity of emulsions with different oil concentration is shown in Table 1. It was discovered that the emulsion with $28 \%$ oil concentration had the highest viscosity, while emulsions with $26 \%$ oil 
concentration had the lowest viscosity $(\alpha=0.05)$. The viscosity of the emulsion was directly proportional to the increase in oil concentration. Higher oil concentration would increase the total of dispersed phase in emulsion, so that the higher density of the emulsion droplets, due to the higher oil concentration, would reduce the flow rate of the emulsion.

Table 1: Emulsion viscosity with different oil concentration

\begin{tabular}{cc}
\hline Oil concentration & Viscosity $(\mathbf{c P})$ \\
\hline $26 \%$ & $972.50 \pm 3.60^{a}$ \\
$27 \%$ & $986.33 \pm 3.31^{b}$ \\
$28 \%$ & $1067.89 \pm 2.61^{c}$ \\
\hline Means with different superscript letter
\end{tabular}

Means with different superscript letter were significantly differenct $(\alpha=0.05)$

\section{Emulsion Stability}

A higher separation fraction means the emulsions are less stable. After 28 days of observation, sign of declining emulsion stability was visible through the separation fraction. However, based on statistical analysis, the stability of emulsions was significantly affected by oil concentration, whereas type of antioxidant and the interaction between oil concentration and type of antioxidant did not significantly affect the stability of emulsions $(\alpha=0.05)$. Stability of emulsions with different oil concentrations is shown in Table 2. The emulsions with $28 \%$ oil concentration had the highest stability, whereas emulsions with $26 \%$ oil concentration had the lowest stability $(\alpha=0.05)$.

Emulsion stability increased with increased concentration of oil in the emulsion. According to Lin (2009), an emulsion containing $70 \%$ milk fat is relatively stable compared with $30 \%$ and $50 \%$ milk fat because of the static state of the droplets due to their density within the system such that the frequency of movement of the droplets that triggers separation decreases.
Table 2: Separation fraction of emulsions with different oil concentration

\begin{tabular}{cc}
\hline Oil concentration & $\begin{array}{c}\text { Separation fraction } \\
(\boldsymbol{\%})\end{array}$ \\
\hline $26 \%$ & $8.82 \pm 0.54^{a}$ \\
$27 \%$ & $7.95 \pm 0.63^{b}$ \\
$28 \%$ & $7.22 \pm 0.53^{c}$ \\
\hline
\end{tabular}

Means with different superscript letter were significantly differenct $(\alpha=0.05)$

\section{Perceived Saltiness of Emulsions}

The intensity of the seasoning emulsion saltiness with different oil concentrations and type of antioxidant was evaluated using a line scale test.

Based on the statistical analysis, the perceived saltiness of the emulsions was significantly affected by oil concentration, whereas the type of antioxidant and the interaction between oil concentration and type of antioxidant did not significantly affect the stability of emulsions $(\alpha=0.05)$. Perceived saltiness of the emulsions with different oil concentration is shown in Table 3. Based on the post hoc test conducted on the effect of the concentration of oil, it was found that the emulsion with $28 \%$ oil concentration had the highest perception of saltiness. Furthermore, evaluation of perceived saltiness of the seasoning emulsions with three different types of oil concentration (A, $\mathrm{B}, \mathrm{C}$ ) and seasoning control (D) were conducted without the use of antioxidants. Sodium in seasoning powder used in the emulsion was reduced by $25 \%$ compared with the control.

Based on statistical analysis of the results in Table 4 , there was a significant difference between the emulsions and the control. The emulsion with $28 \%$ oil concentration had the highest perceived saltiness, which was the same as the control seasoning. This indicated that the formation of oil in water emulsion with $28 \%$ oil concentration could reduce the use of sodium in the instant noodle seasoning by $25 \%$ without giving a different perceived saltiness. The presence of oil could accelerate the distribution of stimulus in the form of $\mathrm{Na}^{+}$ions by opening ion channel $\mathrm{K}^{+}$on the taste buds of the tongue and envelope the tongue. This may reduce the flushing process of the liq- 
uid phase at the surface of the tongue so that the intensity of the saltiness increases (Stevens, Pashler, \& Yantis, 2002; Suzuki, Zhong, Lee, \& Martini, 2014). Increased oil concentration might also improve the concentration of tastants in the liquid phase in the emulsion. Thus, with the same amount of salt, the amount of dissolved salts will be more concentrated in the mouth when the liquid phase (water) in the emulsion is reduced. According to Torrico and Prinyawiwatkul (2015), the increase in concentration of oil in oil in water emulsion might increase the salty taste of the salt in certain concentrations.

Table 3: Line scale test of seasoning emulsions with different oil concentration

\begin{tabular}{cc}
\hline Oil concentration & Sensory score \\
\hline $26 \%$ & $5.93 \pm 0.500^{a}$ \\
$27 \%$ & $6.39 \pm 0.46^{b}$ \\
$28 \%$ & $6.77 \pm 0.56^{c}$ \\
\hline
\end{tabular}

Scale: $0=$ very not salty; $15=$ very salty; means with different superscript letter were significantly different $(\alpha=0.05)$

Table 4: Line scale test of seasoning emulsions with different oil concentration and seasoning control

\begin{tabular}{cc}
\hline Formulation & Sensory score \\
\hline A & $5.98 \pm 0.43^{a}$ \\
B & $6.32 \pm 0.42^{b}$ \\
C & $6.86 \pm 0.47^{c}$ \\
D & $6.79 \pm 0.43^{c}$ \\
\hline
\end{tabular}

Scale: $0=$ very not salty; $15=$ very salty; means with different superscript letter were significantly different $(\alpha=0.05)$ $\mathrm{A}=$ Emulsion with $26 \%$ oil; $\mathrm{B}=$ Emulsion with $27 \%$ oil; $\mathrm{C}=$ Emulsion with $28 \%$ oil; $\mathrm{D}=$ Seasoning powder

\section{Oxidative Stability}

Oxidative stability was observed as shelf-life of the emulsion. The longer shelf-life, the higher oxidative stability of the emulsion. Based on the statistical analysis, the oxidative stability was significantly affected by oil concentration and type of antioxidant individually, whereas the interaction between oil concentration and types of antioxidant did not significantly affect the oxidative stability of the emulsions $(\alpha=0.05)$ (Table 5$)$. Emulsions with $28 \%$ oil concentration had the longest shelf-life compared with the others, moreover the use of either ascorbyl palmitate or mixed tocopherol as antioxidant had a longer shelf-life than the use of natural vitamin $\mathrm{E}$.

Emulsions with $28 \%$ oil concentration had the longest shelf-life which indicated that they had the best oxidative stability. The higher oil concentration increased the dispersed phase in the emulsion so increasing its viscosity and density of droplets in emulsion. Dense spacing reduces space between droplets in the emulsion so that air, as well as other components that act as precursors of oxidation are unable to enter the system and cannot contact the oil in the emulsion. According to Akoh (2005), decreasing the concentration of oil in the sample of oil in water emulsion from $30 \%$ to $10 \%$, causes an increase in the total oxidative value, based on the peroxide and anisidine values of emulsion samples. At increased concentration of oil, the proportion of water fraction decreases with the increase in the oil fraction of the emulsion. As the concentration of water decreases, the soluble prooxidant in water would decrease thus decreasing the amount of free radical generation per droplet. High oil concentration increases the concentration of droplets of oil so that the total generation of free radicals will be decreased when compared with the total number of droplets. Fewer free radical would decrease the rate of oxidation in emulsion thereby increasing emulsion stability against oxidation. According to Mcclements and Decker (2009), when the oil droplet concentration is increased, there is decline in oxidized oil fractions from $43.75 \%$ to $6.25 \%$ in safflower oil in water emulsion containing sucrose.

Oxidative stability of emulsions with different types of antioxidant is shown in Table 6. Emulsions with natural vitamin $\mathrm{E}$ as an antioxidant had the shortest shelf-life, showing that vitamin E was less effective in promoting oxidative stability. The low effectiveness of vitamin E could have 
occured due to the addition of natural vitamin $\mathrm{E}$ which increased the amount of natural tocopherol in oil which resulting prooxidative effect. The addition of natural vitamin $\mathrm{E}$ as an antioxidant could also cause antagonistic interactions with natural antioxidants in the oil. According to Choe and Min (2009), there is an antagonistic interaction between the plant extract rich in polyphenols with $\alpha$-tocopherol in pork fat or sunflower seed oil. It could also be caused due to the fact that natural vitamin $\mathrm{E}$ is less stable than the other two types of antioxidants that were used. The use of mixed tocopherols and ascorbyl palmitate as an antioxidant in the seasoning promoted significantly longer shelf-life. This indicated that both types of antioxidants were good at maintaining the stability of the emulsion instant noodle seasoning against oxidation. Ascorbyl palmitate effectively works as an antioxidant in vegetable oils either alone or in combination with other natural antioxidants. According Shahidi (2015), ascorbyl palmitate synergistically prevents the oxidative reaction with $\alpha$-tocopherol, which is naturally present in corn oil. The tocopherol consists of a mixture of the tocopherol derivatives $\alpha-, \beta-, \gamma-, \delta$ - tocopherol which have antioxidant effects that are influenced by the composition of the mixture. A mixture of oil-soluble tocopherol produces the best protection at a concentration of $16 \mathrm{ppm}$ in mayonnaise, whereas the antioxidant effect is reduced when the concentration is too high or too low.

Table 5: shelf-life of emulsions with different oil concentration

\begin{tabular}{cc}
\hline Oil concentration & shelf-life (days) \\
\hline $26 \%$ & $264.45 \pm 7.54^{a}$ \\
$27 \%$ & $298.52 \pm 8.16^{b}$ \\
$28 \%$ & $322.33 \pm 4.68^{c}$ \\
\hline
\end{tabular}

Means with different superscript letter were significantly differenct $(\alpha=0.05)$

\subsection{Main Research}

Main research aimed to determine the effect of retort processing by using emulsion with $28 \%$
Table 6: shelf-life of emulsions with different types of antioxidant

\begin{tabular}{cc}
\hline Antioxidant & shelf-life (days) \\
\hline Natural vitamin E & $28.88 \pm 30.09^{a}$ \\
Ascorbyl palmitate & $297.62 \pm 23.70^{b}$ \\
Mixed tocopherol & $298.79 \pm 25.26^{c}$ \\
\hline Means with different superscript letter \\
were significantly differenct $(\alpha=0.05)$
\end{tabular}

oil concentration and the antioxidant chosen from preliminary research, tocopherol. Emulsions were retorted and then compared with a control group without retorting. The emulsions were analyzed for their stability, microbial contamination, and perceived saltiness.

\section{Emulsion Stability}

Emulsion stability was evaluated by measuring the level of creaming that occurred on day 0,7 , 14, 21 and 28 based on separation fractions (Figure 1). The higher the separation fraction the less stable the emulsions. Based on the observation for 28 days, it was known that the separation of the emulsion occured and increased during the observation period for both emulsions. Statistical analysis showed that there was no significant difference in the stability between emulsion with or without retort processing $(\alpha=0.05)$ (Figure 2). Both emulsions appeared to have an increased level of separation with the same trend until the end of the observation period. These results may have been obtained due to protein changes in the emulsion during the retorting process. According to Kerry (2012), a thermal process such as retorting could change the structure of secondary, tertiary and quaternary protein which could also break the bonds of the protein so that the protein structure is open. Protein functional and physiological changes could occur due to chemical modification of the amino acid or from protein denaturation during the application of heat.

The heating process affects emulsifier adsorbing at the oil droplet surface. When the absorbed globular protein is heated above the temperature of denaturation, the structure and chemi- 


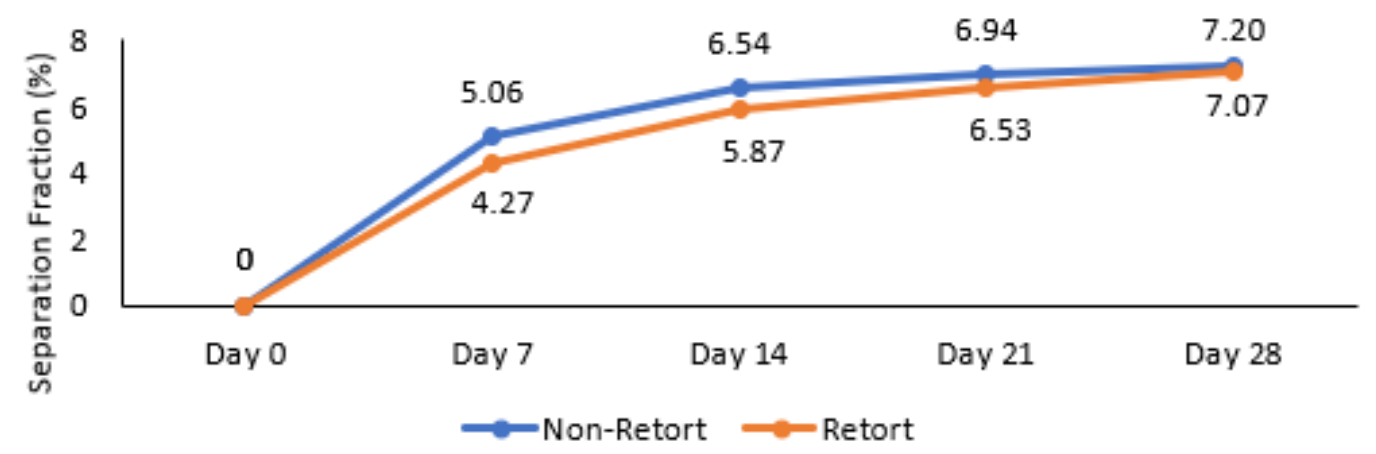

Figure 1: Separation fraction of emulsion with and without retort processing

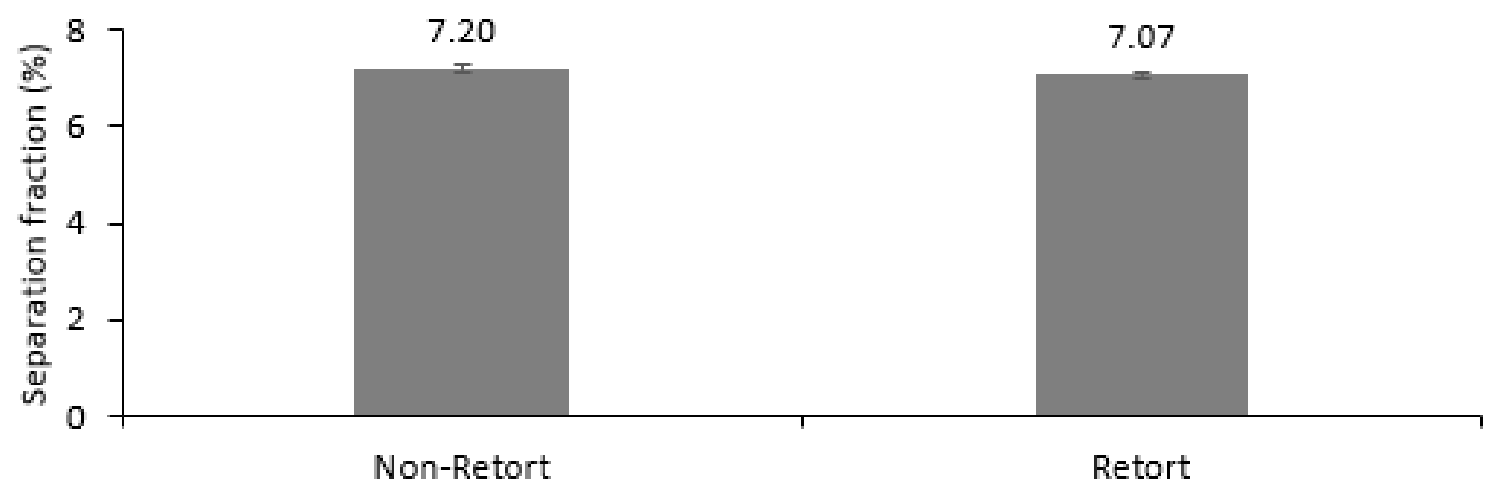

Figure 2: Separation fraction of emulsion with and without retort processing on day 28

Table 7: TPC and YMC of emulsion with and without retort processing

\begin{tabular}{ccccccc}
\hline & \multicolumn{3}{c}{ Non-Retort } & \multicolumn{2}{c}{ Retort } \\
\hline & TPC $(\mathrm{CFU})$ & Yeast $(\mathrm{CFU})$ & Mold $(\mathrm{CFU})$ & TPC $(\mathrm{CFU})$ & Yeast $(\mathrm{CFU})$ & Mold $(\mathrm{CFU})$ \\
\hline Day 0 & $1.74 \times 10^{3 a}$ & 0 & 0 & $0^{b}$ & 0 & 0 \\
Day 7 & $5.26 \times 10^{3 a}$ & 0 & 0 & $0^{b}$ & 0 & 0 \\
\hline
\end{tabular}

CFU - colony forming units. Means different superscript letter on the same row $(\alpha=0.05)$ 
Table 8: Sensory saltiness scores, moisture, and sodium content of emulsion with and without retort processing

\begin{tabular}{lcc}
\hline & Non-Retort & Retort \\
\hline Saltiness & $4.70 \pm 1.02^{a}$ & $5.17 \pm 1.37^{a}$ \\
Moisture Content \% & $33.62 \pm 0.19^{a}$ & $34.78 \pm 0.27^{a}$ \\
Sodium (mg/100g) & $2000.23 \pm 120.68^{a}$ & $1902.17 \pm 104.26^{a}$
\end{tabular}

Saltiness scale: $1=$ very not salty; $7=$ very salty; means with different superscript letter on the same row $(\alpha=0.05)$

cal activity of proteins changes irreversible. Proteins unfold completely and could effectively rearrange all nonpolar amino acid in the oil phase, which decreases the effect of aggregation. At higher temperatures, protein in the interphase membrane would make a more compact layer in the surrounding oil droplet. It would increase droplet density and decrease the probability of creaming. In milk heated between temperatures of $65-80^{\circ} \mathrm{C}$ that the fat droplet size is enlarged by partially denaturing the protein thereby increasing the rate of droplet flocculation and the surface of the droplet becomes more hydrophobic, whereas at higher temperatures $\left(80-90^{\circ} \mathrm{C}\right)$, the size of the droplets become smaller and compact than before (Raikos, 2010). Additionally, protein changes could decrease protein component solubility so the viscosity would increase as well, which stabilizes the emulsion from creaming. According to Liang (2014), the changing in temperature can result in changes to the protein components occuring, such as aggregation, dephosphorization, deamination, polymerization and hydrolysis, all of which affect the nature of the protein component. Crosslinking may occur between the amino acids of protein that can reduce protein solubility.

Complete of partial protein denaturation may involve folding that causes aggregation. Increased in pressure homogenization or the application of heat at a temperature of $90^{\circ} \mathrm{C}$ resulted in denaturation of proteins causing the formation of aggregate particles which increased the viscosity and gelation of the emulsion system (Buxbaum, 2007).

\section{Microbial Contamination}

Total plate count and yeast mold count from the emulsions with and without retorting are shown in Table 7. It was known that microbial contamination increased significantly in the emulsion without retort processing. The retort treatment showed a significant reduction in microbial contamination as seen in total plate count $(\alpha=0.05)$. Retort treatment could produce sterile conditions in the emulsion and maintain that condition until the seventh day of observation. High temperature treatment at $123.5^{\circ} \mathrm{C}$ for 21.5 minutes served as the sterilization process for the emulsion so there was no microbial contamination in the product (Zeuthen \& Bøgh-Sørensen, 2003).

\section{Microbial Contamination}

Total plate count and yeast mold count from the emulsions with and without retorting are shown in Table 7. It was known that microbial contamination increased significantly in the emulsion without retort processing. The retort treatment showed a significant reduction in microbial contamination as seen in total plate count $(\alpha=0.05)$. Retort treatment could produce sterile conditions in the emulsion and maintain that condition until the seventh day of observation. High temperature treatment at $123.5^{\circ} \mathrm{C}$ for 21.5 minutes served as the sterilization process for the emulsion so there was no microbial contamination in the product (Zeuthen \& Bøgh-Sørensen, 2003). 


\section{Perceived Saltiness of Emulsion}

Scoring test of perceived saltiness showed that there was no significant difference between emulsion with and without retort processing $(\alpha=0.05)$ (Table 8 ). The retort process did not affect the intensity of perceived saltiness in seasoning emulsion. The emulsion was stable to heat treatment, so it was not broken and therefore could maintain the function of oil-in-water emulsion that can increase the perception of saltiness. This result was also supported by the moisture and sodium contents that were not significantly different between the seasoning emulsion with and without retort processing (Table 8). It showed that the retort process would still maintain the water concentration within the emulsion as it did not cause evaporation. The retortable pouch consists of several layers based on a layer of aluminum foil that acts as an absolute barrier to mass transfer, light and microorganisms (Shihab, Hafeeda, Kumar, Tamilselvan, \& Nadanasabapathi, 2013), making it impermeable to gas and water. Hence, it could prevent the transmission of water vapour and thus the moisture content of products does not change significantly. The sodium content of seasoning emulsion with and without retort processing was not significantly different (Table 8). Heat treatment such as retorting at $123.5^{\circ} \mathrm{C}$ for 21.5 minutes had no significant effect on the sodium content of the instant noodle seasoning emulsion. Thus, the intensity of the salty taste between emulsions was not significantly different.

\section{Conclusions}

Based on this research, the instant noodle seasoning emulsion with $28 \%$ oil concentration had the highest oxidative stability, stability, and viscosity as well as the highest level of saltiness which was not significantly different from the control seasoning powder without sodium reduction. Moreover, the use of mixed tocopherol as antioxidant in the emulsion produced the highest oxidation stability. Thus, the combination of $28 \%$ oil concentration and mixed tocopherol was the best formulation and used for retort processing. This research showed that retort processing had no significantly effect on the stability of emulsion and the intensity of saltiness in instant noodle seasoning emulsion. However, retort processing did significantly decrease microbial contamination in instant noodle seasoning emulsion based on the total plate counts. Further research is still needed on the application of oil in water emulsion on a low-sodium seasoning instant noodles with the retort process. The influence of retorting on the reduction of sodium in the instant noodle seasoning should be investigated. Further evaluation regarding colour and flavour with the retorting process is required to determine consumer acceptance of the product. In addition, to improve energy and cost efficiency in this application, it is necessary to optimize the treatment retorting to the instant noodle seasoning emulsion. Evaluation of shelf-life to rancidity and flavour acceptance and specific microbial contamination should be done to assess the effectiveness and efficiency of the retort treatment against the commercial standard specification instant noodle seasoning. This would make the expected results more applicable to the instant noodle seasoning emulsion.

\section{Acknowledgements}

This research was supported by PT Nutrifood Indonesia for product development and research on reduction in sodium consumption. The authors want to thank PT Nutrifood Indonesia for kindly providing all the materials and facilities during the research.

\section{References}

Akoh, C. C. (2005). Handbook of functional lipids.

Arnold, M., Teja, T. P., \& Yudianto, D. (2018). Karakterisasi dan Evaluasi Sensori Bumbu Mi Instan Rendah Natrium Berbasis Emulsi Minyak dalam Air (Characterization and Sensory Evaluation of Low Sodium, Oil in Water Emulsion Based Instant Noodles Seasoning ). Indonesian Journal of Food Technology, 1, 1. Retrieved from http : / / indonesianjft . com / ?link = view\&id=JMP-12-17-001 
Bakry, A., Abbas, S., Ali, B., Majeed, H., Abouelwafa, M., Mousa, A., \& Liang, L. (2015). Microencapsulation of oils: A comprehensive review of benefits, techniques, and applications. Comprehensive Reviews in Food Science and Food Safety, 15, 143182. doi:10.1111/1541-4337.12179

BPOM. (2016). Peraturan kepala badan pengawas obat dan makanan republik indonesia nomor 9 tahun 2016 tentang acuan label gizi. Jakarta: BPOM RI.

Buxbaum, E. (2007). Fundamentals of protein structure and function. doi:10.1007/9780-387-68480-2

Choe, E., \& Min, D. (2009). Mechanisms of antioxidants in the oxidation of foods. compr rev food sci f 8:345-358. Comprehensive Reviews in Food Science and Food Safety, 8, 345-358. doi:10.1111/j.1541-4337.2009. 00085. $\mathrm{x}$

Chung, M.-S., Cha, H.-S., Koo, B.-Y., Ahn, P.-U., \& Choi, C.-U. (1991). Determination of optimum sterilization condition for the production of retort pouched curry sauce. Korean Journal of Food Science and Technology, 23.

Daniel, E., Momoh, S., Friday, E., Okpachi, A., \& Ejembi, D. (2014). International journal of medical and applied sciences evaluation of the biochemical composition and proximate analysis of indomie noodle. 3.

Kerry, J. P. (2012). Front matter. In J. Kerry (Ed.), Advances in meat, poultry and seafood packaging (pp. i-iii). Woodhead Publishing Series in Food Science, Technology and Nutrition. doi:10.1533/ 9780857095718.frontmatter

Kilcast, D., \& Subramaniam, P. (2000). The stability and shelf-life of food.

Liang, Y. (2014). Effect of ingredient interactions and heat treatment on the structure and stability of dairy based oil-in-water emulsions: A thesis presented in partial fulfillment of the requirements for the degree of doctor of philosophy in food technology at massey university, palmerston north, new zealand (Doctoral dissertation, Massey University).

Lin, L. (2009). Characterizations of oil-inwater $(O / W)$ emulsions containing differ- ent types of milk fats prepared using rhamnolipids as emulsifiers: $A$ thesis presented in partial fulfillment of the requirements for the degree of Master of Technology in Food Technology at Massey University, Auckland, New Zealand (Doctoral dissertation, Massey University).

Lund, B., Baird-Parker, A. C., Baird-Parker, T. C., Gould, G. W., \& Gould, G. W. (2000). Microbiological safety and quality of food. Springer Science \& Business Media.

Mcclements, D., \& Decker, E. A. (2009). Designing functional foods: Measuring and controlling food structure breakdown and nutrient absorption.

Rahman, T. (2013). RTE and RTC Foods-A New Era in the Processed Food Industry With Special Reference to MTR. International Journal of Management and Social Sciences Research, 2(5), 63-67.

Raikos, V. (2010). Effect of heat treatment on milk protein functionality at emulsion interfaces. a review. Food Hydrocolloids, 24 (4), 259-265. doi:10 . 1016/j . foodhyd . 2009.10.014

Shahidi, F. (2015). Handbook of antioxidants for food preservation, 1-487.

Shihab, M., Hafeeda, Kumar, R., Tamilselvan, K., \& Nadanasabapathi, S. (2013). Development and evaluation of shelf stable retort processed ready-to-drink (rtd) traditional thari kanchi payasam in flexible retort pouches. International Food Research Journal, 20, 1765-1770.

Shin, H. J., Cho, E., Lee, H.-J., Fung, T. T., Rimm, E., Rosner, B., ... Hu, F. B. (2014). Instant noodle intake and dietary patterns are associated with distinct cardiometabolic risk factors in korea. Journal of Nutrition, 144 (8), 1247-1255. doi:10. 3945/jn.113.188441

Stevens, S. S., Pashler, H. E., \& Yantis, S. (2002). Stevens' handbook of experimental psychology: Sensation and perception. John Wiley \& Sons, Incorporated.

Suzuki, A. H., Zhong, H., Lee, J., \& Martini, S. (2014). Effect of lipid content on saltiness perception: A psychophysical study. Journal of Sensory Studies, 29(6), 404412. doi:10.1111/joss.12121 
Torrico, D. D., \& Prinyawiwatkul, W. (2015). Psychophysical effects of increasing oil concentrations on saltiness and bitterness perception of oil-in-water emulsions. Journal of Food Science, 80(8), S1885-S1892. doi:10.1111/1750-3841.12945

Wasowicz, E., Gramza Michalowska, A., Hes, M., Jelen, H., Korczak, J., Malecka, M., ... Zawirska-Wojtasiak, R. (2004). Oxidation of lipids in food. Pol J Food Nutr Sci, 13, 87-100.

Zeuthen, P., \& Bøgh-Sørensen, L. (2003). Food preservation techniques. 